\title{
Perceived Impact Of Environmental Factors On Teaching And Learning Of Physical Education In Rivers State
}

\author{
G. A. Deemua, (Ph.D) \\ Human Kinetics And Health Education \\ Faculty Of Education \\ University Of Port Harcourt
}

\begin{abstract}
This paper examines perceived effects of environmental factors on teaching and learning of physical education and sports in Rivers State. Some of the identified environmental factors negatively affecting teaching and learning of physical education and sports include students' health, school location, socio-cultural beliefs, instructional facilities and community/family background. It is therefore recommended amongst others that the government and stakeholders in education should make the school environment attractive and stimulating and employ good instructional strategies to enhance students' interest, attitudes and achievements in teaching and learning physical education and sports.
\end{abstract}

Keywords: Environmental factors, Teaching, Learning, Physical Education and Sports.

\section{INTRODUCTION}

One of the primary objectives of education is the ability to prepare people most especially the youths for a living. In this case, people should be equipped with skills needed to function in the world of work. Therefore, schools have been able to design their curricula to bring these functions about by their programme offerings and by effective dedication to their implementation. This can be introduced through career education, the type of education which sees the teaching and learning of physical education as a career programme which aims at providing the participants the ample opportunities for a better living and for a living. By this, persons of all ages are prepared for the world of work through equipping them with adequate skills that they need to survive in the ever dynamic society (Okoro, 1991; Amewhule, 2008).

This is particularly important for the youths as they are expected to explore work roles through socialization from the primary school to the University. Ultimately, this prepares them to seek and enter occupations of their choice. All these goals and objectives can be achieved through the school, home, communities and business institutions. It can be seen as an effort on the part of the communities, homes and schools to help the youths and adults better prepare themselves for work through acquisition of adaptable skills, enabling them to change with the changing times in such a manner to make work more rewarding and pleasurable.

Physical education curricular therefore have to be adapted towards ability to adequately prepare and equip individual participants for jobs or make them self employed on graduation. According to Osuala in Amaewhule and Amadi (2016), such curricular imperatives should also embrace new programmes, training methodologies, learning materials, training preparation and so on. Therefore, the researcher maintains that for students to acquire meaningful knowledge and adaptable skills for sustainable achievements in physical education and sports, schools as a matter of fact must be designed to ensure that students are provided with a qualitative and harmonious environment where they can learn and thrive. 
Upu and Okwara (2018:903), posits that environment consist natural, social and the constructed world which include biotic and abiotic factors. School environmental factors on the other hand may be defined as the totality of all the surrounding and activities that go on in the school (Upu \& Okwara, 2018)

This shows that school environmental factors as it influence the teaching and learning of physical education and sports may include classrooms, libraries, quality teachers, teaching methods, school location, student6s' background, physical structures, temperature as well as adequate supervision and motivating of all the activities that go on in the schools. For teachers of physical education to make these environmental factors conducive for the teaching and learning of physical education, they should be able to acquire the qualitative and quantitative body of knowledge about the environment and to be action oriented in improving environmental qualities for effective teaching and learning. In support of this assertion, Amoo (2004) maintains that a harmonious school environment is clean, free from flood and bad odour, well ventilated with adequate supply of light, the air and water are not polluted, the temperature is moderate, and the grass around is properly maintained and has adequate instructional and learning facilities as well as adequate quality personnel.

Many research works have been carried out to address the issue of poor students achievement in physical education and sports, however, most of these works are in the other areas like teaching method, motivation, attitude, physical structures, but little have been done on environmental factors. This prompted the researcher to carry out this work to access the effects of environmental factors on teaching and learning of physical education in Rivers State.

\section{Health Issues and Physical Education Involvement}

Health is a foreign term derived from Anglo-Saxon language which connotes the wholeness of an individual or situation. The World Health Organization (1945) defined health as a state of complete physical, mental and social wellbeing and not merely the absence of disease or infirmity. On this same platform, Dictionarny.com (2016) saw health as the general condition of the body or moral with reference to soundness and vigor; good health; poor health and soundness of body or mind; freedom from disease or ailment. Udoh in Amaeze and Ekechukwu (2016) stressed that health is the quality resulting from the total functioning of the individual in his environment that empowers him to achieve personally satisfying and socially useful life. Health as the name implies is the wholeness of an individual or situation that enables him to function most effectively in the environment that make life interesting and enjoyable. Health is the wellbeing of the body or soul of an individual at a particular point in time. It is only a healthy person that can run, jump, dance, having a sound sleep and live personally satisfying and socially useful life.

The various physical psychological or physiological challenges likely experienced by students participating in physical education and sports are malaria, fever, diarrhea, wounds and injuries, anxiety, lack of good sleep, tiredness and lack of low concentration. These are serious health issues that may optimally mar effective participation of students in physical education and sports. This goes a long way to depitch the fact that in a situation where students, physical educationists, coaches and sports administrators are not provided with an accommodating work environment, may end up achieving little or no success in physical education.

\section{School Location and Physical Education}

Another environmental factor probably might be affecting teaching and learning of physical education is school location. School location as an environmental factor is the demographic area or place where schools are situated. School location may influence students' attitudes and 
academic achievements. This is because in a situation whereby the school is situated in a swampy area where classrooms and playing areas are overflooded with water or noisy area like in the heart of town, near construction sites or near industries/factories where activities disturbing the teaching-learning process is much, students cannot concentrate and do well academically (Upu and Okwara, 2018). In a nutshell; when the playing areas and courts are covered with mud and sandy, it will negatively affect the coaching and training session in preparation for state, nation and international sports competitions. Therefore, there is need to improve the quality of the environment where teachers and learner would thrive for excellence.

\section{Socio-Cultural Environment}

Sports in modern society have become a strong weapon for social integration and massive weapon for cultural assimilation across the entire universe. Through the active participation in physical education and sports, individual students have come to appreciating of living together irrespective of their different geographical locations and orientations. The different environments which individual students come from make them to behave in different ways.

Socio-cultural environments have a powerful impact on the upbringing, achievement and behaviour of the individual students in physical education. The implication of this is the assumption that socio-cultural practices affect the behaviour children develop and the learning and acquisition of valuable skills in sports. This socio-cultural factors comprised of people's attitudes, behaviour patterns, norms and values, traditions and beliefs, lifestyles and demography. All of these factors have a great deal of influence and control over the way physical education has developed in Rivers State.

"Culture is defined as the totality of learned, socially transmitted customs, knowledge, material objects, and behaviour; it includes the ideas, values, customs and artefacts. Culture also refers to the total ways of life of a society" (Boye, 2011).

The culture of a people affects or influence their involvement and participation in sports. The various traditional play activities that transcended into sporting activities in most African traditional society is a reflection of their beliefs and pattern of life. According to Adedeji (1985) the various play activities in form of games and sports in the colonial African setting is a typical reflection of the people's culture. The beliefs held by a society seriously affect their level on teaching and learning of physical and sports involvement. There are culture that prevent ladies from participating in social functions and public engagement while some hold the belief that sports is only for the male folk. When a society or community because of their belief and culture prevent individuals from public engagement it will definitely affect their sports involvement and participation (Boye, 2011 \& Fadoju, 1999).

In contrast to the influence culture to the teaching and learning of physical education and sports, religious beliefs also influence students learning and participation in sports. Religious beliefs are part of culture. Some religious beliefs prohibit women from participating in public functions, and this will definitely affect involvement and participation in sports. In most cases, some parts of Northern Nigeria and the world in general, ladies are not allowed to put on cloths that are capable of exposing some parts of their body. Irrespective of the fact that there is dress code for every sports involvement which negates the religious beliefs of those of contrary belief. Deemua and Fadoju (2018) also shared the same belief that religion is another strong factor that provides an avenue for children, youths and adults alike to socialize. Even though some types of religion forbid people, particularly women, from wearing some types of dresses, yet children and youths improve on their interpersonal relationships through sporting 
programmes organized by religious organizations. By every standard dressing is part of a people's culture, sports has dress code which must be obeyed by all individuals.

\section{Instructional Facilities and Physical Education}

Basic instructional facilities development are crucial part of teaching and learning physical education and sports; this is because meaningful learning hardly takes place without the use of basis infrastructural facilities. In view of this assertion, Amoo (2004), maintains that a harmonious school environment with adequate instructional and learning facilities as well as adequate quality personnel facilitate effective teaching and learning process.

School sports/instructional facilities therefore constitute the major component in learning environments and teachers in the attempt to transfer learning are expected to among others to provide variety, create opportunities, for students to practice, and utilize the available sports facilities and equipment for demonstration. Where these facilities are not available learning experiences and increase performance in physical education and sports will be obstructed (Deemua, 2017).

Sports facility/instructional facilities are paramount in the secondary school process to function effectively. Sport facilities is defined as areas that are constructed or maintained to allow people to participate in sports and recreational activities of their choice under a close monitoring and supervision of a teacher. Unfortunately, observations have shown that sports/instructional facilities in most Rivers State Secondary Schools are grossly inadequate due to the large number of students' enrolment in schools. This resulted to overcrowded situation because instructional facilities designed for a few number of students have been manipulated by the crowd most especially during training and practical sessions. When students are overcrowded in a class to receive lessons, it affects teaching and learning process a situation that generally militate against the acquisition of skills, knowledge and learning experiences in an attempt to cope with standards, values and needs of the society.

Arguably, sports facilities situation in public secondary schools in Rivers State has been unsatisfactorily interms of maintenance and this resulted in more funds needed for major repairs, replacement or even builds new ones. Sport facilities include the gymnasium, swimming pool, indoor sports hall, tennis and volleyball courts, athletic field and all materials that are engaged in the school system to bring about effective teaching and learning (Deemua, 2017). The provision and maintenance of these facilities remain an integral part of the overall management of the school as they serve as pillar of support for effective teaching and learning of physical education and sports programmes in secondary schools in Rivers State.

\section{Community/Family Background and Physical Education and Sports Involvement}

There are the opinions that both maladjustment and adjustment in sports and physical education could be traced to different community/family background. Ugwu and Onwulebe (2012), defined family as a pattern of relationship a home is structured. They maintained that family changes in structure as the relationship is affected by certain factors. The environment in which an individual lives greatly affects his behaviour as regards sports involvement and participation.

The topography of a place influence participation and involvement in sports. Omoruan (1996) stated that culture of any given people affect their sporting activities. Community based sports provides the early sports experiences for individuals in the community; hence, many community oriented sports are the first to be assimilated by the people living in that community. For instance, in a Traditional African Society, men and women do engage in 
various forms of sports during their leisure time. In Ekerenior, Sagbama and Nembe among others in Bayelsa State and Ikwerre, Ogoni, Kalagbari, Okrika and Bonny (Rivers State) culture, wrestling, swimming, boat regatta, dancing and running are the first sports to be assimilated by the people living in that community.

Many African communities have variety of play and sporting activities that are peculiar to their customs and traditions. Many of such play activities are incorporated into their festival and cultural activities. Individual living in such communities are thought the rudiment of such play activities that are transferred from one generation to the others. When individuals are thought and introduced to the cherished communal play activities they are being socialized into sports which eventually influenced the individual choice and participation in physical activities and sports.

The family is known to be generally responsible for early sports socialization, including modeling, reinforcement and the shaping of the observed behaivour (Harris, 1994). Parents involvement in sports is of great influence to children early life sports experiences. Parents who are interested in sports will likely provide children that will be interested in sports. However, such interests will be as a results of the motivation and encouragement that will be received or given by the parents. In line with this assertion, Harris (1994) maintains that learners who receive parental support will be motivated to perform better than those learners who are not motivated by their parents and that interest in sport by children is usually preceded by the parents' interest. For instance, a father that plays tennis as a recreational sports will likely encourage his children to play tennis. This will positively influence the child to develop interest in tennis when he grows up. To be skillful in any particular activity one must be influenced by factors surrounding that particular activity, such factors are responsible for induction into the activity.

\section{CONCLUSION}

Environments are crucial part of teaching and learning physical education and sports. This shows that meaningful learning hardly takes place without a healthy community and school environments. Unfortunately, observation has shown that health factors, school location, sociocultural beliefs, instructional facilities and community/family background are situations. That generally, militates against effective teaching and intellectual development of the students in physical education and sports involvement in most of the secondary schools in Rivers State. If these environmental factors are properly harnessed, have a potential of improving students' attitudes, interest and achievements in physical education and sports.

\section{RECOMMENDATIONS}

Based on the above observations, the researcher pointed out that:

1. Secondary schools in Rivers State should be designed to ensure students are provided with harmonious environment for the effective teaching and learning of physical education and sports.

2. Good instructional strategies that have the potential of improving students' attitudes, interest and achievements in physical education should be employed.

\section{References}

Adedeji, J.A. (1985). The teaching of physical and health education. Ibadan: Heinnman publishers.

Amaewhule, W.A. (2005). An introduction to vocational education and administration. Owerri: Civincs Publishers. Amaewhule, B. \& Amadi, K. (2016). Education and environment. A Journal of Institute of Education, University of Education. 9(1\&2) 259-264. 
Amaeze, F.E. \& Ekechukwu, R.O. (2016). Health factors and effective counselling services in Secondary Schools in Imo State, Nigeria. A Journal of Institute of Education, University of Port Harcourt. 9(1\&11) 27-34.

Amoo, B.O. (2000). Environmental sustainability in Nigeria. Educational Technology Centre, Lagos, State University (LASU) Nigeria.

Amoo, B.O. (2004). Environmental sustainability in Nigeria Educational Technology Centre, Lagos State University (LASU) Nigeria.

Boye, T.E. (2011). Human Kinetics: Social-psychological/family life and health perspectives. Warri: Masega Publishers.

Deemua, G.A. (2017). Provision and routine maintenance of sports facilities in Public Secondary Schools in Rivers State. African Journal of Educational Research and Development (AJERD) 9(IA) 71-76.

Deemua, G.A. \& Nwankwo, G.O. (2018). Perceived effects of religious and cultural belief on students' participation in sports among Universities in the Geo-political zones, Nigeria. International Journal of Scientific Research in Education 11(3b) 613-620.

Dictionary.com (2016).Retrieved 23rd April; 2016 from http://www.dictionary.com/browse/health

Fadoju, A.O. (1999). Introduction to sociology of sports. In O.A. Moronkola (Ed.), Essential of Human Kinetics and Health Education. Ibadan: Coadat Publication.

Harris, O. (1994). Race, Sports and social support. Sociology of Sports Journal. 11, 40-5.

Okoro, M.O. (1991). Principles and methods in Vocational and technical education. Lagos: Abic Publishers.

Omoruan, J.C. (1996). A handbook on physical education and recreation. Zaria: Asemowu Publishers.

Osuala, E.C. (2004). Foundation of vocational education. Enugu: Cheston Agency Limited.

Ugwu, C.J. \& Onwutebe, (2012). Relationship between family structure and drug addiction of adolescents students of Bayelsa State. DELSU Journal of Educational Research and Development, 11(1), 108-115.

Upu, F.T. \& Okwara, O.K. (2018). Perceived effects of environmental factors on teaching and learning of Basic Science and Technology in Benue State, Nigeria. International Journal of Scientific Research in Education. 11(5) 902-911. 